\title{
The Ways and Means of Review on Expert Opinion
}

\author{
Shaofang Wang* \\ Department of Forensic Science, China
}

*Corresponding author: Shaofang Wang, Hubei University of Police, Wuhan,

Hubei, P. R. China.

Received Date: November 23, 2018

Published Date: December 17, 2018

\begin{abstract}
Forensic identification is an activity in which experts use science and technology to analyze and judge the material evidence involved in lawsuits and provide opinions. In many countries, expert opinion is one kind of legal evidences. When it is applied in court, it must possess evidence qualifications and probative force. The validity of expert opinions is directly related to the disclosure of case facts, the realization of justice, and the protection of civil legitimate rights and interests. In order to improve the efficiency of expertise review and avoid incorrect acceptance of expert opinions without reliability and validity, the review system must be improved and perfected comprehensively. And lots of provisions about the review should be refined further, such as how to perfect the expert assistant system, establish the review rule, select the review method, and so on.
\end{abstract}

Keywords: Way; Review; Expert opinion; Forensic science

\section{Introduction}

There is much strong litigation value from scientific and reliable expert opinions which play a vital role in the determination on case facts, the protection of legitimate rights and interests of the parties, the maintenance of social equity and justice. Before expert opinions are accepted, judicial staff must strictly examine and judge their competence of evidence and their probative force. In order to improve the efficiency of expertise review and avoid incorrect acceptance of expert opinions without reliability and validity, the review system must be improved and perfected comprehensively. And lots of provisions about the review should be refined further.

\section{Perfecting of Expert Assistant System}

Expert assistants are special participants in litigation. In order to give full play to the auxiliary role of forensic technology and professional knowledge they have mastered, legislators and administrators should proceed from the national conditions, improve the management system, and clarify the status, qualifications and evidence effectiveness of expert assistants.

\section{Defining the status of expert assistants in litigation}

Expert assistants are different from forensic examiners and technical consultants employed by judges themselves, and also different from expert jurors. They refer to the specialists who have expertise and can help explain professional issues in the case. They are employed by all parties, such as the prosecutor, the suspect, the defendant, the victim, the defender and the agent in criminal cases, and the litigant and his agent in civil cases. Expert assistants may not appear in court. They will provide services of technical consultation only for their clients and participate in cross-examination activities. If expert assistants are invited to appear in court, they must obtain the approval of judicial authority. Therefore, expert assistants can be identified as special participants in litigation.

Expert assistants may interpret other expert's opinions and analyze possible questions in the expertise before a court hearing or during the process of lawyers acting as agents. In order to ensure that expert assistants can accurately find out the problems existing in others' opinions, they must be given certain rights, such as understanding the basic information of cases, the circumstances of the parties concerned, the specific process of identification (initiating, intrusting, accepting, implementing, etc.), the basic condition of forensic institutions and examiners, looking up the record of examination, inquiring and debating the examiners, express their own viewpoint upon others' conclusion, refusing the entrustment which violated the law or morality, gaining legal remuneration, and so on. At the same time, expert assistants must also fulfill certain obligations, such as honestly introducing their academic background and achievements, truthfully answering the questions raised by parties concerned with the identification, objectively explaining forensic technology and expertise, properly keeping relevant consultation materials, and stringently keeping 
state and business secrets and personal privacy which they know during their work. In order to effectively avoid or reasonably resolve some disputes, it is better for the clients to sign a contract or agreement with the expert assistant. And both parties strictly fulfill their respective obligations in accordance with the contents of the contract or agreement.

\section{Setting up the qualification requirements for expert assistants}

It is one of the topics concerned by the legal theorists and judicial practitioners that what conditions the "person with expertise" should meet to become an expert assistant. At present, there are two viewpoints: "theory of qualification" and "theory of ability". Scholars who hold the former argue that auxiliaries must possess the qualification of forensic experts, that is, examiners who have been registered. It is convenient not only to strengthen the management of examiners' participation in litigation, but also to facilitate the parties and agents to find and understand relevant information of the examiners. Scholars with the later viewpoint claim that it is enough for the assistants to get special knowledge and assistant capacity. And there is not necessary to set up strict regulations beforehand since the scope of expert assistants is far greater than that of forensic examiners. In addition to the latter, assistants may also be other persons with technology, expertise and skills. It is competent that assistants, hired by parties, can help to explain and cross-examine specific maters of the case. Some other factors should be not compulsive to become a criterion of qualifications, for instance, the way to be entitled is to rely on years of educational background or long-term practical experience.

In the view from the author of this article, the two viewpoints both have their own advantages and disadvantages. As far as the "theory of qualification" is concerned, it is simple, easy-operate and convenient-manage to determine whether a person can become an expert assistant or not. But its scope is too narrow, which will reject a large number of people with strong professional ability from litigation. This is not in line with the purpose of setting up an expert Assistant system. As far as "theory of competence" is concerned, judging whether a person can become an expert assistant depends on his technology, expertise and skills, which has expanded the scope of candidates who may become an expert assistant, but is not conducive to practical operation and management. The reason is that it is difficult for parties and agents to make an accurate judgment on whether a person really has grasped forensic technology, expertise and skills because of the lack of professional knowledge. Therefore, the two viewpoints can be combined to stipulate the qualifications of expert assistants from two aspects: basic requirements and procedural requirements. There are some basic requirements which auxiliaries must meet in deed, such as possessing a national license for forensic identification, being registered as a forensic examiner; or holding a senior technical title in the field of her (or his) study; or having been engaged in professional and technical work for more than 10 years; and so on. Also there are several procedural requirements necessarily. First, the parties should submit an application to the court, which signifies the personal information, professional title, technical qualification, academic background, occupational experience of the applicant or other information that can prove her (or his) competence and expertise in the domain accordingly. Secondly, the court should organize two parties to conduct a qualification review through evidence exchange. After examining, if one party argues that the applicant is not qualified as an expert, he may submit an objection to the court. Then a decision will be made by the judge in final. During the examining, the judge should check not only the basic conditions of the applicant, but also whether she (or he) is in the interest with litigants and examiners of the case. Anyone who has a direct interest with litigants and examiners should be refused to participate in cross-examination to ensure that the expert assistant can be in a neutral position. Of course, if a litigant requires the expert to solve many technical problems before the trial other than needs them to take part in a cross-examination, the qualifications of the assistant employed need not be defined at all.

\section{Using the opinion of expert assistant rationally}

The opinion of expert assistant without evidence effect does not belong to the category of statutory evidence, which must not be used as proof. It can help litigants to improve the understanding about professional knowledge, aid judges to review expert opinions, and become a reference for the judge to determine case facts. In practice, litigants and judges should correctly deal with the status of expert assistants and reasonably use their opinions. It is not appropriate to exaggerate the legal function of expert assistants, nor rely too much on their opinions, so as to avoid rejecting accurate and reliable opinions of forensic examiner.

\section{Establishing of Review Rule for Expert Opinion}

One of the manifestations of legal certainty is the existence of evidence rules. The rule of evidence reflects people's pursuit to the goal of ruling by law to a certain degree, which main function is to prevent judges from making arbitrary decisions in the process of free evaluation on evidence. Therefore, it is necessary to set up various situations that may arise in judicial practice from the perspective of regulation, to establish a clear and strict system of procedural rules, to build the rule of judge's free evaluation of evidence on the basis of unified norms, to reduce the scope and latitude of the judge's discretion to the highest extent. In the activities of seeking regular pattern and affirming objective fact, the process of judge's free evaluation of evidence should be externalized objectively and standardized procedurally as far as possible, so as to ensure the realization of substantive justice from procedural justice. Therefore, the review of expert opinions must be restricted by certain rules to prevent the emergence of unconstrained free evaluation of evidence or arbitrary decision.

\section{Rule of probative force without precondition and priority}

Expert opinions, as the same as other kinds of evidences, have no predetermined probative force. Whether or not they have proof power and the strength of evidence need to be cross-examined by the prosecution and the defense, and the referee will make a comprehensive judgment combined with other evidences. The purpose of formulating rules of unpredictable and preferential 
proof power is to require judicial staff to strictly examine the objectivity and relevance of expert opinions while they are being applied, and to make relatively free judgments on the probative force based on their own experience and common sense of axioms.

\section{Rule of validity level without difference}

In forensic practice, it often happens that many contradictory or inconsistent expert opinions are made on the same materials in litigation. How to protect the judicial authority of forensic identification, enhance the social identity, eliminate the confusion caused by the contradiction of several opinions, has always been one of the focuses in the academic circles of forensic science and evidence science. Some scholars believe that a hierarchical system about evidence validity of conclusions should be established, which divides the identification institutions or examiners into several levels. The conclusions of different levels have different effect of evidence. The opinions from high-level identification institutions or examiners are higher than those from low-level ones in probative force. This kind of rating system about evidence effect has relative rationality itself. However, some limitations will be brought at the same time. Generally speaking, there are better equipments, more examiners with higher ability and capability at the superior identification bodies, which handling with more difficult cases. Compared with the general lower examination institutions, the accuracy of conclusions may be higher. Nevertheless, this possibility does not form an inevitable canon. As a matter of fact, sometimes it happened that opinions made by lower institutions were correct. Contrarily, opinions from higher identification bodies could be faulty. Accurate conclusion with objectivity and equality depends upon an exact grasp to scientific truth and objective facts. It is not related to the social status of examiner and the grade of identification institution. Forensic identification is a scientific and empirical activity about the research on material evidence. The strength of probative force of expert opinion can only be determined by the judge according to axiomatic principles and empirical knowledge, combining with other proof in the whole case, and through his free evaluation of the evidence [1-2].

\section{Rule of the disclosure of free evidence evaluation on probative force}

As far as the legislative situation in the world is concerned, judges in many countries and regions have been granted the discretion to evaluate expert opinions. However, these opinions are formed on the basis of certain scientific principles and professional knowledge after analyzing and exploring in compliance with legal procedures. There must be some reasonable gauges for judges to arbitrate the strength of probative force of expert opinion and whether or not accept them as proof, other than relying entirely on personal preference or sudden impulse. Therefore, in many countries and regions, the rule of the disclosure of free evidence evaluation has been formulated, which requires that if an expert opinion is refused to be applied, sufficient reasons must be given, and the authentication process, inference results and chief gauges should be disclosed truthfully. At present, there is not yet similar provision in the field of Chinese legislation. Some scholars have pointed out that, according to the law, all evidence verified to be true should be reviewed and judged by judicial personnel. And the admission and discretion should be decided independently. Whether or not the acceptance is made must be subject to certain restrictions. Especially to the key litigation evidence, if they are refused without sufficient reasons, it will inevitably cause strong reaction from the litigation parties, and the legal supervision organ will also raise objections. In judicial practice, judges have a certain degree of arbitrariness in the choice of expert opinions, which brought about more serious problems, such as repeated identification, multi-head identification, etc. Therefore, it is absolutely necessary to draw lessons from the extraterritorial rule on the disclosure of free evidence evaluation, to entrust referendaries with the discretion to judge expert opinions in principle. At the same time, the referendaries must provide detailed reasons that whether expert opinions are accepted or not [3-4].

\section{Choice of Review Method for Expert Opinion}

Expert opinions have become the key evidences in many cases with the establishment of modern trial system. Frequently, the evaluation on the validity of expert opinions has turned into the focus of disputes between the prosecution and the defense in litigation. In order to accurately grasp the probative force of expert opinions and correctly understand their litigation value, lots of scientific review methods must be adopted. And much attention must be paid to several significant review sections.

First, the examiner's academic background and professional ability should be reviewed. The academic background is the basis and guarantee for examiners to carry out forensic work. The professional ability and practical experience can play an important role in guaranteeing the scientificity of testimony. In assessing the probative force of expert opinions, it is necessary to censor:

(1) whether the examiner has excellent knowledge background and high practical ability to solve certain specialized problems in a case.

(2) whether she (or he) possesses the qualifications of an expert, how about the academic influence and popularity.

(3) whether she (or he) has the accomplishment of seeking truth from facts and respecting science highly, how about the professional ethics.

(4) whether there is a legal avoidance situation to the examiner.

(5) whether there is any external interference during the examining process and

(6) whether she (or he) has performed false examination.

Second, the material evidence should be checked and arbitrated. Material evidence, including suspected material and known sample, must be collected and extracted according to legal procedures. And their objective condition must meet the requirements of the examining methods used. To the suspected materials, the methods of discovering, extracting, preserving and treating should be checked, for instance, whether they have been damaged, polluted, changed, lost partly or totally, and whether their 
characters, quantity and quality are qualified for identification, etc. To the known samples, the focus of review is that whether their source is true and reliable, their quantity is sufficient, and they are comparable.

Third, the examining methods and procedures should be reviewed and judged. Scientific examining method is the guarantee to make a correct opinion. If the measure and process are not appropriate, it will lead to errors or deviations in a final conclusion. In assessing the probative force of expert opinions, it is crucial to censor:

a) whether the equipment and technical means used by the examiner are advanced and reliable

b) whether the examining course are standardized

c) whether the analyzing methods are suitable

d) whether the thinking mode is scientific, and

e) whether the examining activities are adhered to materialistic dialectics and guided by the theory of identity cognizance.

Fourth, the basis of expert opinions should be reviewed. There are two main aspects: one is the principle of identification; the other is the specific conditions of materials and their characteristics. The probative force and legal credibility of expert opinions can be reflected through scientific basic. It is only when the examining basis is sufficient can the examiner's understanding about material characteristics become deeper. And their conclusion may own stronger probative force and higher credibility. Therefore, much more attention should be paid to check:

1.whether the examiner has known well the overall characteristics of materials, rather than only focuses on individual or a few characteristics.

2.whether the interpretation about the match and discrepancy of characteristics is comprehensive and reasonable.

3.whether the literary expression of the opinion is clear accurate and logistic.

Fifth, the relationship between expert opinion and other evidences should be reviewed and judged. Everything in the world is related to each other. It is also one of the best ways to distinguish the truth from the false through finding out the causal relationship between things. While expert opinion being judged, it is necessary to analyze other evidences in the case, combine all proof into a chain, and find out whether they can connect and corroborate each other. If the evidences are consistent with each other, it can usually confirm that the expert opinion is accurate. If there are contradictions or inconsistencies between expert opinion and other evidences, the specific reasons should be ascertained to determine whether the expert opinion is wrong or other evidence is not true. Maybe both are correct or wrong, but there is other hidden information in the case. When the inconsistencies between expert opinion and other evidences happen, investigators, prosecutors, judges and examiners must not complain or accuse each other groundless, nor set aside expert opinion and refuse to investigate or make a supplementary identification or re-identification, but imperturbably and carefully analyze the reason [5-6].

\section{Conclusion}

Forensic experts play an important role and undertake the task of safeguarding judicial justice in litigations. Judicial authority can ascertain the truth of affairs, reveal the relationship between evidences and facts, make fair decisions, and achieve judicial justice ultimately through applying expert opinions.

From the view of science and technology, informatization and modernization have become a main theme of epoch development with the deepening of social transformation currently. The means and measures of committing crime are becoming more and more cunning and intricate. Many examining methods have obviously fallen behind and cannot solve the professional problem completely and effectively. It is essential to further strengthen the study on the theory and measures of forensic identification, comprehensively improve the professional capacity and technical standards, and increasingly enhance the accuracy and reliability of expert opinions, in order to meet the requirement of litigious activities in the new period.

From the perspective of judicial system, legalization and standardization have become the main direction of social development with the changing of national policy concerned and the promoting of judicial system reform. It is not only feasible but also necessary to draw lessons from the legislative experience and management system among countries in the world and further perfect the system of forensic identification in many aspects, based on the current situation of legal system construction and combined with the overall goal of legal reform. At the same time it is significant to improve the service ability of forensic identification, promote the standardized operation and sound development of forensic science. The litigants can be guaranteed to acquire judicial services with high quality by these ways. And the judicial authority can review expert opinions efficiently and accept them properly.

\section{Acknowledgement}

None.

\section{Conflict of Interest}

No conflict of interest

\section{References}

1. Michael Bowers C (2014) Forensic Testimony Science, Law and Expert Evidence San Diego, CA: Academic Press, USA.

2. Daniel A Bronstein (2012) Law for the Expert Witness, Boca Raton, Florida, US: CRC Press.

3. DN Vieira (2013) Forensic Systems and Forensic Research: An International Perspective. In: Douglsa $\mathrm{H}$ Ubelaker (ed.), Forensic Science: Current Issues, Future Directions. Hoboken, NJ: John Wiley \& Sons, Ltd, USA.

4. Jack V Matson (2013) Effective Expert Witnessing: Practices for the 21st Century, Boca Raton, Florida, US: CRC Press, USA. 
5. Clive Gamble, Gaille MacKinnon Ms (2014) New Standards for Professional Practice in Forensic Anthropology Introduced in the United Kingdom. Australian Journal of Forensic Sciences 46(2).
6. Reinoud D Stoel, Itiel E Dror, Larry S Miller (2014) Bias among Forensic Document Examiners: Still a Need for Procedural Changes. Australian Journal of Forensic Sciences 46(1). 